\title{
BMJ Open Unequal access and use of contraceptives among parenting adolescent girls in sub-Saharan Africa: a cross-sectional analysis of demographic and health surveys
}

\author{
Bright Opoku Ahinkorah (D) , ${ }^{1}$ Matthew Tobiloba Obisesan, ${ }^{2}$ \\ Abdul-Aziz Seidu (1) , ${ }^{3,4,5}$ Anthony Idowu Ajayi (1) ${ }^{6}$
}

To cite: Ahinkorah B0, Obisesan MT, Seidu A-A, et al. Unequal access and use of contraceptives among parenting adolescent girls in sub-Saharan Africa: a cross-sectional analysis of demographic and health surveys. BMJ Open 2021:11:e051583. doi:10.1136/ bmjopen-2021-051583

- Prepublication history and additional supplemental material for this paper are available online. To view these files, please visit the journal online (http://dx.doi.org/10.1136/ bmjopen-2021-051583).

Received 23 March 2021 Accepted 16 August 2021

\section{Check for updates}

(C) Author(s) (or their employer(s)) 2021. Re-use permitted under CC BY-NC. No commercial re-use. See rights and permissions. Published by BMJ.

For numbered affiliations see end of article.

Correspondence to Dr Abdul-Aziz Seidu; abdul-aziz.seidu@stu.ucc. edu.gh

\section{ABSTRACT}

Objective We examined the divergent patterns, prevalence and correlates of contraceptive use among parenting adolescents in sub-Saharan Africa using the Demographic and Health Survey datasets of 17 countries.

Design We included a weighted sample of 9488 parenting adolescent girls in our analysis. Current contraceptive use was defined as the use of any methods to delay or avoid getting pregnant at the survey time. We reported the prevalence of any contraceptive use for all countries and used multilevel binary logistic regression analysis to examine the individual and contextual factors associated with contraceptive use.

\section{Outcome measures Contraceptive use.}

Results We found an overall contraceptive prevalence of $27.12 \%$ ( $\mathrm{Cl} 27.23 \%$ to $28.03 \%$ ) among parenting adolescent girls in sub-Saharan Africa, ranging from $70.0 \%(\mathrm{Cl} 61.76 \%$ to $77.16 \%)$ in South Africa to only $5.10 \%$ (Cl $3.04 \%$ to $8.45 \%$ ) in Chad. The prevalence of contraceptive use was lowest in West andCentral Africa, with most countries having less than $20 \%$ prevalence. Increasing age (adjusted OR (aOR)=1.46, 95\% Cl 1.28 to 1.65$)$, being married (aOR=1.63, $95 \% \mathrm{Cl} 1.43$ to $1.87)$, having a secondary or higher level of education ( $\mathrm{aOR}=2.72,95 \% \mathrm{Cl} 2.25$ to 2.3.27), and media exposure (aOR=1.21, 95\% Cl 1.08 to 1.36), were associated with higher odds of contraceptive use in the pooled data but preference for a higher number of children (more than five children) (aOR=0.61, 95\% $\mathrm{Cl} 0.52$ to 0.72 ) was related to lower likelihood of use. Significant heterogeneity was observed in the country-level disaggregated results.

Conclusion African countries differ widely when it comes to contraceptive use among parenting adolescent girls, with only three countries having a relatively high prevalence of use. The governments of countries in subSaharan Africa, particularly those in West and Central Africa, should invest in expanding access to contraceptives for adolescent mothers to prevent repeat pregnancy and improve the overall well-being of parenting adolescent girls.

\section{STRENGTHS AND LIMITATIONS OF THIS STUDY}

$\Rightarrow$ The use of large survey data that are nationally representative and the use of a robust statistical method that considered both individual and contextual level factors are important strengths of this study.

$\Rightarrow$ However, the measure of contraceptive use relied on self-reporting, which is subjected to social desirability bias and could result in under-reporting of use.

$\Rightarrow$ Also, due to the cross-sectional nature of this study, causal link cannot be established.

\section{BACKGROUND}

Despite many decades of governments' and international development partners' interventions, adolescent childbearing remains a burdensome public health problem in sub-Saharan Africa (SSA). ${ }^{1}$ Existing interventions, ${ }^{2}$ though unequally implemented across SSA countries, have only resulted in a slight decline in adolescent birth rate. ${ }^{1}$ Between 2000 and 2019, adolescent fertility rate only declined from 128.2 per 1000 girls to 99.6 per 1000 girls in SSA. ${ }^{3}$ Countries like the Central African Republic (229 per 1000 girls), Mozambique (194 per 1000 girls), Chad (179 per 1000 girls), Mali (174 per 1000 girls), Angola (163 per 1000 girls), South Sudan (158 per 1000 girls), Madagascar (152 per 1000 girls) and Liberia (150 per 1000 girls) have the highest adolescent birth rates globally. ${ }^{1}$ Even though some of these pregnancies occur within the context of marriage, approximately half of adolescent pregnancies in low-and middle-income countries are unintended. ${ }^{4}$ Lack of access to contraceptive information and services, exposure to sexual violence, poverty and restrictive cultural norms and policy context are among the 
reasons for the high rate of adolescent childbearing in SSA. ${ }^{5-11}$

Adolescent childbearing has deleterious consequences, not only on the girls and their babies but also on society. ${ }^{12} 13$ Early childbearing is associated with a greater risk of maternal mortality, unsafe abortion, pre-eclampsia/eclampsia, bleeding during pregnancy, vesicovaginal fistula and prolonged and obstructed labour. ${ }^{4} 12$ 14-16 Also, infants of adolescent mothers are more likely to be born with low birth weight, birth injury, congenital abnormalities and neonatal mortality. ${ }^{17-19}$ Besides its health consequences, adolescent childbearing is linked to school dropout. Failure to re-enter school means losing significant investments that would prepare them for the labour force. ${ }^{20} 21$ Studies have also shown that adolescent childbearing results in poor socioeconomic outcomes, including teen mothers being more likely to live in poverty, unemployed, earning lower salaries and less educational accomplishments than adult mothers. ${ }^{21-23}$ Similarly, the disadvantages that early childbearing confers manifest in their children. A study has shown that children of adolescent mothers' academic achievement never reach the level of their peers' with adult mothers. ${ }^{24}$ Furthermore, teenage mothers' children are more likely to become teenage parents themselves. ${ }^{23}$ Therefore, adolescent childbearing is a threat to realising demographic dividend and 'the Agenda 2063, the Africa we want' despite SSA's youth bulge. Agenda 2063 is the continent's strategic framework for inclusive and sustainable social and economic development between 2013 and 2063. It recognises ending harmful social norms and cultural practices, and violence against women and girls, and achieving gender parity as key to socioeconomic development.

Repeat pregnancy remains common in the SSA context, although rarely studied and addressed. A study has shown that short birth spacing is more prevalent among adolescent mothers compared with adults in SSA. ${ }^{25}$ Several millions of adolescent mothers in SSA are at risk of repeat pregnancy because they are not using any contraceptive methods. ${ }^{10}$ Without intervening, these girls would face repeat pregnancy and all its adverse maternal and child health outcomes, including higher risk of pre-eclampsia, high blood pressure, premature rupture of membranes, preterm birth, low birth weight, stillbirth and neonatal mortality. ${ }^{26} 27$ While the policy change processes to prevent early unintended pregnancy has been slow due opposition to comprehensive sexuality education and provisioning of contraceptives to minors, ${ }^{28-30}$ little advocacy efforts are directed at preventing repeat pregnancy among parenting adolescent girls. This is the case even though preventing repeat pregnancy among adolescent mothers could be critical to ensuring school re-entry, adequate birth spacing, vocational skill uptake and gender equality. ${ }^{31-33}$ Contraceptive use could provide adolescent mothers with the opportunity to make informed decisions to improve their psychological well-being, promote the free expression of sexual desires and aid their decision about when to have their second child. ${ }^{34}{ }^{35}$ Adolescent mothers are generally regarded as emancipated minors, and advocating for their contraceptive use is less controversial. Without investing in their contraceptive use, repeat pregnancy is more likely, school re-entry is less likely, and poverty is more or less guaranteed. ${ }^{4}$

The lack of focus on expanding access to contraceptives among parenting adolescents is due in part to limited evidence on their contraceptive use. Limited studies have explored contraceptive use among parenting adolescent girls in SSA. As a result, gaps exist in our understanding of the pattern and differences in contraceptive use among parenting adolescent girls in the region. Some SSA countries have invested heavily in providing contraceptives for parturient women, including adolescent mothers. ${ }^{36}$ However, other countries have not significantly invested in ensuring mothers and particularly parenting adolescent girls have access to contraceptives. ${ }^{37}$ We expect that contraceptive use among parenting adolescents will mirror the contraceptive policy landscape in SSA, with countries having progressive policies recording a high rate of contraceptive uptake and those without policies or restrictive policies having a lower rate of uptake. This study explores the divergent patterns and prevalence of contraceptive use among parenting adolescents in SSA using cross-sectional Demographic and Health Survey (DHS) data.

\section{METHODS \\ Data source}

We analysed data of 17 countries with recent DHS data (2015-2019). DHS is a nationally representative survey collected every 5 years across low-income and middleincome countries. Countries were included in the study if they had complete information on all the variables included in this study and have recent DHS (2015-2019). Based on these inclusion criteria, we excluded Mozambique since it had no observations for the ideal number of children, one of the variables considered in this study. The countries included are Angola, Cameroon and Chad from Central Africa; Benin, Guinea, Mali, Sierra Leone and Nigeria from West Africa; Burundi, Ethiopia, Rwanda, Tanzania and Uganda from East Africa; and Zambia, Zimbabwe, Malawi and South Africa from Southern Africa. The dataset is freely available for download at: https://dhsprogramcom/data/available-datasetscfm. Our analysis is designed to illustrate the within and between-country inequalities in contraceptive uptake among parenting adolescent girls in SSA. While the need to ensure adolescents have access to contraceptive information and services is paramount, we argue that advocating for policies and guidelines that expand access to contraceptives among parenting adolescent girls is a more realisable goal given the sociocultural and religious context of SSA. Our findings will help advocates, policymakers and developmental partners set their priorities 
Table 1 Sample distribution by country

\begin{tabular}{|c|c|c|c|}
\hline Survey countries & $\begin{array}{l}\text { Survey } \\
\text { year }\end{array}$ & $\begin{array}{l}\text { Weighted } \\
\text { sample }\end{array}$ & Percentage \\
\hline \multicolumn{4}{|l|}{ Central Africa } \\
\hline Angola & 2016 & 907 & 9.56 \\
\hline Cameroon & 2018 & 523 & 5.51 \\
\hline Chad & 2015 & 818 & 8.62 \\
\hline \multicolumn{4}{|l|}{ West Africa } \\
\hline Benin & 2018 & 440 & 4.64 \\
\hline Guinea & 2018 & 441 & 4.65 \\
\hline Mali & 2018 & 507 & 5.35 \\
\hline Nigeria & 2018 & 1043 & 10.99 \\
\hline Sierra Leone & 2019 & 586 & 6.18 \\
\hline \multicolumn{4}{|l|}{ East Africa } \\
\hline Burundi & 2017 & 212 & 2.23 \\
\hline Ethiopia & 2016 & 288 & 3.04 \\
\hline Rwanda & 2015 & 150 & 1.59 \\
\hline Tanzania & 2016 & 533 & 5.62 \\
\hline Uganda & 2016 & 729 & 7.69 \\
\hline \multicolumn{4}{|l|}{ Southern Africa } \\
\hline Malawi & 2016 & 1109 & 11.68 \\
\hline South Africa & 2016 & 176 & 1.86 \\
\hline Zambia & 2018 & 664 & 7.00 \\
\hline Zimbabwe & 2015 & 361 & 3.80 \\
\hline
\end{tabular}

and develop appropriate interventions for enhancing use of contraceptives among parenting adolescents.

\section{Study population}

The population for this study was parenting adolescent girls aged 15-19. We included girls as respondents only if they were aged 15-19 years and had one or more children. We excluded pregnant adolescent girls and those with no children. Thus, the study sample was a weighted distribution of 9488 parenting adolescent girls (see table 1). Details of the DHS's sampling methodology and data collection are published elsewhere. ${ }^{38} 39$

\section{MEASURES}

\section{Outcome variable}

The outcome variable for the study was current use of contraceptives among parenting adolescent girls. The variable current contraceptive use was derived from a question that elicited information on whether respondents or their partners are currently doing something or using any method to delay or avoid getting pregnant at the survey time. Responses to this question were coded as 'no method', 'folkloric method', 'traditional method' and 'modern method'. The modern methods included female sterilisation, male sterilisation, intrauterine device, injectables, implants (Norplant), contraceptive pill, condoms, emergency contraception, standard day method, vaginal methods (foam, jelly, suppository) and lactational amenorrhoea method. Country-specific modern methods and respondent-mentioned other modern contraceptive methods (including cervical cap, contraceptive sponge and others) were also regarded as modern contraceptives. Periodic abstinence (rhythm, calendar method), withdrawal (coitus interruptus) and country-specific traditional methods of proven effectiveness were considered traditional methods. Locally described methods and spiritual methods of unproven efficacy, such as herbs, amulets and gris-gris, were the folkloric methods. ${ }^{38}$ The existing DHS variable on contraceptive use did not include pregnant women and those who had never had sex. To obtain a binary outcome, all respondents who said they used 'no method' were put in one category and were given the code ' $0=$ No'. In contrast, those who were using either folkloric, traditional or modern method were also put into one category and given the code ' $1=$ Yes'.

\section{Independent variables}

Nine independent variables, grouped into individual and contextual level factors, were considered in this study. These variables were not determined a priori, but were selected based on their significant associations with contraceptive use among adolescent girls in previous studies. $^{40-42}$

\section{Individual-level factors}

The individual-level factors were age, marital status, level of education, parity, exposure to media and ideal number of children. Age was grouped as 15-17, and 18-19. Marital status was recoded into never married, married, cohabiting, and separated/widowed/divorced. Level of education was coded as no education, primary and secondary/ higher. Parity was recoded as one birth and two or more births. Respondents were asked how often they listened to radio, watched television and read newspaper. For each of these questions, the responses were (not at all, less than once a week, at least once a week and almost every day). Exposure to media was coded as 'yes' for adolescent girls who either read newspapers, listened to the radio and watched television at least once a week, less than once a week and almost every day and 'no' for those who did not read newspaper/magazine, listen to the radio or watch television at all. The ideal number of children was coded as $0-3,4-5$ and 6 or more.

\section{Contextual-level factors}

The contextual-level factors were wealth index (poorest, poorer, middle, richer and richest), place of residence (urban and rural) and subregion (West Africa, East Africa, Central Africa, and Southern Africa).

\section{Statistical analyses}

We calculated descriptive statistics to report on the prevalence of contraceptive use among parenting adolescent 
girls and presented adolescent birth rates in the selected SSA countries. Then, we used bivariate analysis to show the distribution of contraceptive use across the individual and contextual level factors and estimated Pearson's $\chi^{2}$ test of independence $\left(\chi^{2}\right)$ at a $p$ value of less than 0.05 to show significant factors. Next, variance inflation factor (VIF) was used to check for multicollinearity and there was no evidence of high collinearity (mean $\mathrm{VIF}=1.17$, maximum $\mathrm{VIF}=1.37$, and minimum $\mathrm{VIF}=1.03$ ). After this, we carried out a multilevel binary logistic regression analysis to examine the individual and contextual factors associated with contraceptive use using four models. Model 0 showed the variance in contraceptive use attributed to the clustering of the primary sampling units (PSUs) without the explanatory variables. Model 1 and model 2 contained the individual-level and contextual-level factors, respectively, while model 3 contained all the individual and contextual-level factors. The Stata command 'melogit' was used in fitting these models. We used Akaike's Information Criterion (AIC) tests for model comparison. Finally, we stratified our analysis by country to examine the heterogeneity in predictors of contraceptive use among parenting adolescent girls in all countries. All the results were presented using adjusted ORs (aOR) at $95 \%$ confidence interval (CI). Sample weight (v005/1 $000000)$ and the 'svy' command were used to correct for over and under-sampling and the complex survey design, respectively, to improve our findings' generalisability. The paper was written following the Strengthening Reporting of Observational Studies in Epidemiology reporting guidelines.

\section{Patient and public involvement}

Patients and the public were not involved in the design and conduct of this research.

\section{RESULTS}

\section{Descriptive findings}

Contraceptive use was relatively low in 14 of the 17 countries included. We found an overall contraceptive prevalence of $27.12 \%$ (27.23 to 28.03) among parenting adolescent girls in SSA, ranging from $70.0 \%$ (61.76 to 77.16) in South Africa to only $5.10 \%$ (3.04 to 8.45) in Chad. Modern contraceptives were the most used contraceptive types in all countries studied (25.99\% (25.11 to 26.89)) compared with traditional methods (1.13\% (0.93 to 1.36$)$ ). The contraceptive prevalence mirrors the current adolescent birth rates in many countries considered in this study. For instance, Chad, with the lowest prevalence of contraceptive use, had the highest adolescent birth rate (179 births per 1000 adolescents aged 15-19) (table 2).

\section{Distribution of contraceptive use across individual and contextual factors of parenting adolescent girls in sub- Saharan Africa}

Contraceptive use among parenting adolescent girls was higher among those aged 18-19 (29.6\%), with secondary/higher education (35.2\%), cohabiting (28.6\%), with one birth (28.4\%), exposed to media $(30.9 \%)$ and who considered 0-3 children as ideal $(38.6 \%)$ compared with their counterparts. Parenting adolescent girls in the richest wealth quintile (33.4\%), who lived in urban areas $(28.5 \%)$ and in Southern Africa $(55.5 \%)$ had a higher prevalence of contraceptive use. The $\chi^{2}$ analysis showed association between the individual and contextual factors and contraceptive use, except for marital status (table 3).

\section{Multilevel multivariable findings}

After controlling for all the individual and contextual variables (model III), all variables except parity and residence, had statistically significant influence on contraceptive use among parenting adolescent girls. With the individual-level factors, parenting adolescent girls aged 18-19 (aOR=1.46, 95\% CI 1.28 to 1.65$)$ had higher odds of using contraceptive compared with those aged 15-17. Parenting adolescent girls with secondary/higher education were more likely to use contraceptives compared with those with no formal education $(\mathrm{aOR}=2.72,95 \%$ CI 2.25 to 2.3.27). The odds of contraceptive use was higher among parenting adolescent girls who were exposed to media compared with those who had no exposure (aOR=1.21, 95\% CI 1.08 to 1.36). The odds of contraceptive use was also higher among cohabiting $(\mathrm{aOR}=1.85$, 95\% CI 1.56 to 2.18 ) and married (aOR $=1.63,95 \%$ CI 1.43 to 1.87 ) adolescent girls compared with those who are never married. The use of contraceptives was lower among those who considered six or more children as ideal ( $\mathrm{aOR}=0.61,95 \%$ CI 0.52 to 0.72 ) compared with those whose ideal number of children was 0-3.

With the contextual factors, parenting adolescent girls in the richest wealth quintile had the highest odds of contraceptive use compared with those in the poorest quintile (aOR=1.46, 95\% CI 1.18 to 1.81 ), and those in Southern Africa were more likely to use contraceptives compared with those in West Africa $(\mathrm{aOR}=6.65,95 \%$ CI 5.65 to 7.82 ).

Each of the models explained between $2 \%$ and $3 \%$ of the variations in contraceptive use. As shown in model 0 , the statistically significant differences in the clustering of the PSUs account for the variations in contraceptive use. The final model (model 3) was considered the best fit model as it had the highest log-likelihood $(-4500.2)$ and the lowest AIC (9040.5; table 4).

The regional disaggregated results show that age, marital status, level of education, exposure to media and wealth index were associated with contraceptive use in West Africa; age, marital status, level of education, ideal number of children and wealth index were associated with contraceptive use in East Africa; age, marital status, level of education, exposure to media, ideal number of children and wealth status were associated with contraceptive use in Central Africa; and age, marital status, level of education, ideal number of children and place of residence were associated with contraceptive use in Southern 
Table 2 Contraceptive prevalence among parenting adolescent girls in sub-Saharan Africa

\begin{tabular}{|c|c|c|c|c|}
\hline Survey countries & Contraceptive use & Modern & Traditional & $\begin{array}{l}\text { Adolescent birth rates } \\
\text { (per } 1000 \text { girls)* }^{*}\end{array}$ \\
\hline \multicolumn{5}{|l|}{ Central Africa } \\
\hline Cameroon & 24.25 (19.78 to 29.37 ) & 19.73 (15.95 to 24.14$)$ & 4.52 (2.79 to 7.25$)$ & 119 \\
\hline Chad & 5.10 (3.04 to 8.45$)$ & 3.93 (2.59 to 5.93 ) & 1.17 (0.30 to 4.26$)$ & 179 \\
\hline Guinea & $15.62(11.40$ to 21.03$)$ & $15.18(11.04$ to 20.50$)$ & 0.44 (0.10 to 1.89$)$ & 120 \\
\hline Mali & 18.46 (14.65 to 23.00$)$ & 16.87 (13.22 to 21.29$)$ & 1.59 (0.64 to 3.85$)$ & 174 \\
\hline Nigeria & 6.42 (4.85 to 8.47$)$ & 4.93 (3.66 to 6.61 ) & 1.49 (0.87 to 2.56$)$ & 120 \\
\hline Sierra Leone & 23.33 (19.55 to 27.59$)$ & 23.33 (19.55 to 27.59$)$ & 0.00 (0.00 to 0.00$)$ & 101 \\
\hline Rwanda & 34.46 (26.67 to 43.18$)$ & 32.40 (24.93 to 40.88$)$ & 2.06 (0.67 to 6.20$)$ & 41 \\
\hline Tanzania & 26.46 (22.00 to 31.47$)$ & 25.25 (20.72 to 30.38$)$ & $1.22(0.44$ to 3.31$)$ & 139 \\
\hline Uganda & 33.22 (28.91 to 37.83$)$ & $31.92(27.62$ to 36.56$)$ & 1.29 (0.70 to 2.38$)$ & 132 \\
\hline \multicolumn{5}{|l|}{ Southern Africa } \\
\hline Malawi & 55.69 (52.00 to 59.33$)$ & 55.05 (51.36 to 58.68$)$ & 0.65 (0.24 to 1.73$)$ & 138 \\
\hline South Africa & 70.02 (61.76 to 77.16$)$ & 70.02 (61.76 to 77.16$)$ & 0.00 (0.00 to 0.00$)$ & 71 \\
\hline Zambia & 44.71 (40.07 to 49.47$)$ & 44.44 (39.79 to 49.19$)$ & 0.27 (0.07 to 1.11$)$ & 141 \\
\hline Zimbabwe & 67.58 (62.05 to 72.66$)$ & 66.81 (61.27 to 71.93$)$ & 0.77 (0.18 to 3.22$)$ & 78 \\
\hline All countries & 27.12 (27.23 to 28.03$)$ & 25.99 (25.11 to 26.89$)$ & 1.13 (0.93 to 1.36$)$ & \\
\hline
\end{tabular}

Source: UN Population Fund, UN Department of Economic and Social Affairs, Population Division 2018.

${ }^{*}$ Adolescent birth rates

Africa. This shows that the factors associated with contraceptive use vary by subregions (table 5 ).

However, there were variations in the significance, strength and direction of the association between contraceptive use and the individual-level and contextual-level factors when the results were disaggregated by country. Adolescent mothers aged 18-19 were more likely to use contraceptive compared with those aged 15-17 only in Ethiopia, Mali, Chad, Tanzania, and Zambia. In Malawi, Rwanda, Uganda, Zambia and Zimbabwe, never married adolescent mothers were less likely to use contraceptives compared with those in other marital status categories. However, in Sierra Leone, married and cohabiting parenting adolescent girls were less likely to use contraceptives compared with never-married women. The association between marital status and contraceptive use did not reach a significant level in the remaining countries.

In Angola, Mali, Malawi, Nigeria and Sierra Leone, level of education was significantly correlated with contraceptive use. Parity only showed significant association in Ethiopia, where adolescent mothers with two or more births were less likely to use contraceptives compared with those with one delivery. Adolescent mothers exposed to media in Chad and Zambia were more likely to use contraceptives compared with those who had no media exposure. Parenting adolescent girls who considered 4-5 children and 6 or more children as their ideal number of children were less likely to use contraceptives compared with those who considered 0-3 children as ideal number of children in Burundi and Tanzania, respectively. However, adolescent mothers in Guinea with six or more children as their ideal number of children were more likely to use contraceptives. Wealth index was positively and significantly associated with contraceptive use in Angola, Benin, Ethiopia, Guinea, Nigeria, Sierra Leone, Tanzania, Uganda, and Zambia but was negatively associated with contraceptive use in Zimbabwe. In terms of urban-rural differences in contraceptive use, a significant association was found only in Malawi, where adolescent mothers in rural areas were less likely to use contraceptives compared with those in urban areas (see online supplemental tables 1-4).

\section{DISCUSSION}

Adolescent childbearing is far too common in SSA, with adverse health and socioeconomic implications. Interventions are rightly concentrated on preventing early 
Table 3 Distribution of contraceptive use across individual and contextual factors of parenting adolescent girls in subSaharan Africa

\begin{tabular}{|c|c|c|c|c|}
\hline Variables & Weighted N & Weighted \% & Contraceptive use & $\chi^{2}$ (P value) \\
\hline Age & & & & $62.9(<0.001)$ \\
\hline $15-17$ & 2679 & 28.2 & 21.0 & \\
\hline $18-19$ & 6809 & 71.8 & 29.6 & \\
\hline Marital status & & & & $2.83(0.418)$ \\
\hline Never married & 2612 & 27.5 & 28.0 & \\
\hline Married & 4811 & 50.7 & 26.3 & \\
\hline Cohabiting & 1456 & 15.4 & 28.6 & \\
\hline Widowed/divorced/separated & 609 & 6.4 & 26.4 & \\
\hline Level of education & & & & $576.9(<0.001)$ \\
\hline No education & 2514 & 26.5 & 9.5 & \\
\hline Primary & 4079 & 43.0 & 32.2 & \\
\hline Secondary/higher & 2895 & 30.5 & 35.2 & \\
\hline Parity & & & & $36.7(<0.001)$ \\
\hline One birth & 7901 & 83.3 & 28.4 & \\
\hline Two births or more & 1587 & 16.7 & 21.0 & \\
\hline Exposure to media & & & & $42.8(<0.001)$ \\
\hline No & 6834 & 72.0 & 25.7 & \\
\hline Yes & 2654 & 28.0 & 30.9 & \\
\hline Ideal number of children & & & & $535.7(<0.001)$ \\
\hline $0-3$ & 2835 & 29.9 & 38.6 & \\
\hline $4-5$ & 3995 & 42.1 & 29.2 & \\
\hline 6 or more & 2658 & 28.0 & 11.8 & \\
\hline Wealth index & & & & $58.9(<0.001)$ \\
\hline Poorest & 2252 & 23.7 & 23.2 & \\
\hline Poorer & 2392 & 25.2 & 24.9 & \\
\hline Middle & 2022 & 21.3 & 29.0 & \\
\hline Richer & 1689 & 17.8 & 29.2 & \\
\hline Richest & 1133 & 11.9 & 33.4 & \\
\hline Place of residence & & & & $3.9(0.049)$ \\
\hline Urban & 2603 & 27.4 & 28.5 & \\
\hline Rural & 6885 & 72.6 & 26.6 & \\
\hline Subregions & & & & $7.35(<0.001)$ \\
\hline West Africa & 3017 & 28.9 & 13.7 & \\
\hline East Africa & 1912 & 29.3 & 31.2 & \\
\hline Central Africa & 2248 & 17.9 & 12.4 & \\
\hline Southern Africa & 2310 & 23.9 & 55.5 & \\
\hline
\end{tabular}

Source: Demographic and Health Surveys.

unintended pregnancy; however, preventing repeat pregnancy among the teeming population of parenting adolescent girls is equally important. We examined the divergent patterns and prevalence of contraceptive use among parenting adolescents in 17 SSA countries. Our analyses show an overall relatively low prevalence of contraceptive use among parenting adolescents (21.1\%) across SSA. Sub-Saharan African countries differ widely when it comes to contraceptive use among parenting adolescent girls, with only three countries having a relatively high prevalence of use. While approximately 7 out of 10 adolescent mothers are using any form of contraceptives in Zimbabwe and South Africa, less than 1 in 10 are using them in Angola, Chad, Benin, and Nigeria. The contraceptive prevalence rates in SSA appears to be inversely proportional to the adolescent fertility rates, 
Table 4 Mixed-effect results on individual and contextual factors associated with contraceptive use among parenting adolescent girls in sub-Saharan Africa

\begin{tabular}{|c|c|c|c|c|}
\hline Variables & $\begin{array}{l}\text { Model } 0 \\
\text { aOR }(95 \% \mathrm{Cl})\end{array}$ & $\begin{array}{l}\text { Model } 1 \\
\text { aOR }(95 \% \mathrm{Cl})\end{array}$ & $\begin{array}{l}\text { Model } 2 \\
\text { aOR }(95 \% \mathrm{Cl})\end{array}$ & $\begin{array}{l}\text { Model } 3 \\
\text { aOR }(95 \% \mathrm{Cl})\end{array}$ \\
\hline \multicolumn{5}{|l|}{ Age } \\
\hline $18-19$ & & $1.50^{\star * \star}(1.33$ to 1.69$)$ & & $1.46^{\star \star \star}(1.28$ to 1.65$)$ \\
\hline \multicolumn{5}{|l|}{ Marital status } \\
\hline Cohabiting & & $1.24^{\star \star}(1.06$ to 1.45$)$ & & $1.85^{\star \star \star}(1.56$ to 2.18$)$ \\
\hline Widowed/divorced/separated & & $1.04(0.84$ to 1.29$)$ & & $0.92(0.74$ to 1.16$)$ \\
\hline \multicolumn{5}{|l|}{ Level of education } \\
\hline No education & & Ref & & Ref \\
\hline One birth & & Ref & & Ref \\
\hline Two births or more & & $0.78^{\star \star}(0.68$ to 0.90$)$ & & $0.92(0.79$ to 1.07$)$ \\
\hline \multicolumn{5}{|l|}{ Exposure to media } \\
\hline No & & Ref & & Ref \\
\hline Yes & & $1.23^{\star \star \star}(1.10$ to 1.37$)$ & & $1.21^{\star *}(1.08$ to 1.36$)$ \\
\hline \multicolumn{5}{|l|}{ Ideal number of children } \\
\hline $0-3$ & & Ref & & Ref \\
\hline $4-5$ & & $0.60^{* * *}(0.54$ to 0.67$)$ & & $0.90(0.80$ to 1.02$)$ \\
\hline Richest & & & $1.81^{\star \star \star}(1.47$ to 2.22$)$ & $1.46^{\star \star \star}(1.18$ to 1.81$)$ \\
\hline \multicolumn{5}{|l|}{ Place of residence } \\
\hline Urban & & & Ref & Ref \\
\hline Rural & & & $0.81^{\star \star \star}(0.71$ to 0.93$)$ & $0.88(0.76$ to 1.02$)$ \\
\hline \multicolumn{5}{|l|}{ Subregions } \\
\hline West Africa & & & Ref & Ref \\
\hline East Africa & & & $2.86^{\star \star \star}(2.46$ to 3.33$)$ & $2.16^{\star \star \star}(1.82$ to 2.56$)$ \\
\hline Central Africa & & & $0.81^{*}(0.69$ to 0.96$)$ & $0.79^{\star}(0.66$ to 0.95$)$ \\
\hline Southern Africa & & & $9.03^{\star \star \star}(7.86$ to 10.39$)$ & $6.65^{\star \star \star}(5.65$ to 7.82$)$ \\
\hline \multicolumn{5}{|l|}{ Random effect result } \\
\hline PSU variance $(95 \% \mathrm{Cl})$ & 0.07 (0.04 to 0.14$)$ & $0.09(0.05$ to 0.17$)$ & $0.08(0.04$ to 0.17$)$ & 0.09 (0.05 to 0.18$)$ \\
\hline ICC & 0.02 & 0.03 & 0.03 & 0.03 \\
\hline LR test & $\chi 2=11.0^{\star \star \star}$ & $\chi 2=14.4^{\star \star \star}$ & $\chi 2=10.6^{\star \star \star}$ & $\chi 2=10.9^{\star \star \star}$ \\
\hline Wald $\chi^{2}$ & Reference & $829.2^{\star \star \star}$ & $1366.3^{\star \star \star}$ & $1465.3^{\star \star \star}$ \\
\hline \multicolumn{5}{|l|}{ Model fitness } \\
\hline Log-likelihood & -5481.4 & -4920.4 & -4665.9 & -4500.2 \\
\hline
\end{tabular}


Table 4 Continued

\begin{tabular}{cllll}
\hline Variables & $\begin{array}{l}\text { Model 0 } \\
\text { aOR }(95 \% \text { Cl) }\end{array}$ & $\begin{array}{l}\text { Model 1 } \\
\text { aOR (95\% Cl) }\end{array}$ & $\begin{array}{l}\text { Model 2 } \\
\text { aOR (95\% Cl) }\end{array}$ & $\begin{array}{l}\text { Model 3 } \\
\text { aOR (95\% Cl) }\end{array}$ \\
\hline AIC & 10966.7 & 9864.9 & 9351.9 & 9040.5 \\
\hline N & 9488 & 9488 & 9488 & 9488 \\
\hline
\end{tabular}

Model 0: empty model without any explanatory variable.

Model 1: adjusted for individual-level variables.

Model 2: adjusted for contextual level variables.

Model 3: adjusted for individual and contextual level variables.

Source: demographic and Health Surveys

${ }^{\star} p<0.05,{ }^{* \star} p<0.01,{ }^{\star \star *} p<0.001$.

AIC, Akaike's Information Criterion; aOR, adjusted OR; ICC, intraclass correlation; LR test, likelihood ratio test; PSU, primary sampling unit; Ref, reference category.;

with countries with very low contraceptive uptake having high adolescent childbearing rate. One could argue that underutilisation of contraceptives is responsible for the high adolescent fertility rates in these countries. ${ }^{10}$ With the low contraceptive uptake observed among adolescent mothers in these countries, repeat pregnancy and its dire consequences are more likely, relative to countries where more adolescent mothers are using contraceptives. Studies that examine birth spacing in SSA have shown that women are postponing second birth in Zimbabwe and South Africa, but short birth spacing is common in Chad and especially among young people. ${ }^{25} 4344$

The wide differences in contraceptive use among parenting adolescent girls across SSA also typify the varying sociocultural norms and attitudes towards contraceptives and the policy landscape of adolescent sexual and reproductive health. ${ }^{45}$ Those with progressive sexual and reproductive environment, laws and policies also have a higher contraceptive prevalence than those with restrictive legal and policy landscape ${ }^{3647}$ South Africa, for example, had the highest prevalence of parenting adolescents' contraceptive use, which is due to their progressive sexual and reproductive health policies, ${ }^{47}$ wide availability of contraceptives in all health facilities, and contraceptive counselling. ${ }^{36}$ A study shows that most parturient women initiated contraceptives immediately after the delivery in South Africa irrespective of age ${ }^{36}$ Also, South Africa's policies allow adolescents aged 12 to access hormonal contraceptives without parental consents, provided they have sufficient maturity and mental capacity, and there is medical advice and examination. ${ }^{48}$ However, in Chad, where contraceptive prevalence is lowest, women face many barriers including ongoing humanitarian crisis, frequent and consistent stockouts, and limited domestic resources allocated to family planning. ${ }^{49}$

Our study illustrates the within-country inequalities in access to contraceptives among parenting adolescents in SSA. Adolescent mothers with secondary school education or higher were more likely to use contraceptives in Angola, Cameroon, Mali, Malawi and Nigeria, which underscore the inequality in access to contraceptives in these countries. Education is vital for positive health outcomes. ${ }^{50}$ As such, the education of girls is crucial for their empowerment and development. ${ }^{51}$ An empowered girl child can make an informed decision for her health and assert her agency and rights to the highest attainable health. ${ }^{52}$ The goal of educating all girls is enormous and worth pursuing, but some interventions could immediately improve outcomes. Increasing access to contraceptive counselling and commodities, for example, could instantly increase uptake. This was done to greater effect in Zimbabwe and South Africa, where adolescent mothers can access contraceptives irrespective of their educational achievements.

Parenting adolescents belonging to the highest wealth class were more likely to use contraceptives in Angola, Benin, Ethiopia, Guinea, Nigeria, Sierra Leone and Tanzania. The wealth inequality in access to contraceptives among parenting adolescents in these countries suggests the need for government in these countries to make contraceptives freely available to all adolescents irrespective of their socioeconomic status. Making contraceptives freely available and counselling girls about the benefits should be an important first step in these countries. Yet other barriers exist, including poor healthcare infrastructure and inaccessibility to health facilities. ${ }^{53} 54$ The benefit of contraceptives for women's health is too significant to allow income as a barrier limiting access. South Africa has managed to eliminate inequality in access to contraceptives. Other countries should follow the example of South Africa.

We found no evidence of rural and urban differences in access to contraceptives in the sub-Saharan African countries studied, except for Malawi. This finding contrasts with previous studies that suggest rural and urban inequality in access to contraceptives in SSA. ${ }^{53} 54$ However, this is an encouraging result that indicates that if access to contraceptives is increased in rural areas, the level of use will be the same as in urban areas. The relationship between marital status and contraceptive use is mixed. While never married adolescent girls in Malawi, Rwanda, Uganda, Zambia and Zimbabwe were less likely to use contraceptives compared with those in other marital status categories, the contrast 
Table 5 Multivariable models showing factors associated with contraceptive use among parenting adolescent girls in subSaharan Africa by subregions

\begin{tabular}{|c|c|c|c|c|}
\hline \multirow[b]{3}{*}{ Variables } & \multicolumn{4}{|l|}{ Country } \\
\hline & West Africa & East Africa & Central Africa & Southern Africa \\
\hline & aOR $(95 \% \mathrm{Cl})$ & aOR (95\% Cl) & aOR $(95 \% \mathrm{Cl})$ & aOR $(95 \% \mathrm{Cl})$ \\
\hline $15-17$ & Ref & Ref & Ref & Ref \\
\hline $18-19$ & $1.34^{*}(1.02$ to 1.75$)$ & $1.64^{\star \star *}(1.25$ to 2.16$)$ & $1.50^{*}(1.09$ to 2.05$)$ & $1.32^{\star \star}(1.09$ to 1.61$)$ \\
\hline Never married & Ref & Ref & Ref & Ref \\
\hline Married & $0.49^{\star \star \star}(0.38$ to 0.64$)$ & $2.22^{\star \star \star}(1.63$ to 3.01$)$ & $0.59^{\star \star}(0.39$ to 0.87$)$ & $3.30^{\star \star \star}(2.69$ to 4.04$)$ \\
\hline Cohabiting & 0.71 (0.38 to 1.08$)$ & $2.73^{\star \star \star}(2.03$ to 3.67$)$ & 0.95 (0.69 to 1.32$)$ & $3.01^{\star \star \star}(1.92$ to 4.74$)$ \\
\hline Widowed/divorced/separated & $0.46^{*}(0.22$ to 0.95$)$ & $1.62^{*}(1.10$ to 2.41$)$ & $0.42^{*}(0.20$ to 0.90$)$ & $1.16(0.84$ to 1.61$)$ \\
\hline \multicolumn{5}{|l|}{ Level of education } \\
\hline \multicolumn{5}{|l|}{ Parity } \\
\hline One birth & Ref & Ref & Ref & Ref \\
\hline Two births or more & 1.09 (0.80 to 1.46$)$ & 0.87 (0.65 to 1.18$)$ & 1.15 (0.83 to 1.59$)$ & $0.83(0.62$ to 1.19$)$ \\
\hline \multicolumn{5}{|l|}{ Exposure to media } \\
\hline No & Ref & Ref & Ref & Ref \\
\hline Yes & $1.29^{*}(1.03$ to 1.62$)$ & $1.02(0.82$ to 1.27$)$ & $2.11^{\star \star \star}(1.50$ to 2.97$)$ & $1.11(0.92$ to 1.36$)$ \\
\hline \multicolumn{5}{|l|}{ Ideal number of children } \\
\hline $0-3$ & Ref & Ref & Ref & Ref \\
\hline Richer & $3.48^{\star \star \star}(2.29$ to 5.30$)$ & $1.56^{\star}$ (1.11 to 2.21$)$ & 1.15 (0.64 to 2.06$)$ & 0.89 (0.66 to 1.18$)$ \\
\hline Richest & $3.43^{\star \star \star}(2.10$ to 5.59$)$ & $2.21^{\star \star \star}(1.46$ to 3.35$)$ & $1.93^{*}(1.03$ to 3.62$)$ & 0.76 (0.53 to 1.09$)$ \\
\hline \multicolumn{5}{|l|}{ Place of residence } \\
\hline Urban & Ref & Ref & Ref & Ref \\
\hline Rural & 1.02 (0.77 to 1.34$)$ & 0.91 (0.66 to 1.27$)$ & $1.00(0.70$ to 1.41$)$ & $0.77^{*}(0.60$ to 0.98$)$ \\
\hline
\end{tabular}

${ }^{*} \mathrm{p}<0.05,{ }^{* *} \mathrm{p}<0.01,{ }^{* * *} \mathrm{p}<0.001$

aOR, adjusted OR.

is true in Sierra Leone. Parenting adolescent girls in a marital relationship are more at risk of repeat pregnancy because of more exposure to sex compared with single adolescent mothers. Nevertheless, it is important that all adolescent mothers use contraceptives because of their numerous benefits.

\section{Policy implications}

Low prevalence of contraceptive use among adolescent mothers has implications for repeat pregnancy, short birth spacing, school re-entry, economic empowerment of girls, gender equality and overall well-being. If parenting adolescents engage in sex without using any contraceptive methods, they will likely get pregnant. The pregnancy may even carry greater risk than the previous, especially if not well spaced. With more children to care for, the possibility of returning to school diminishes, so is their likelihood of escaping poverty. Investing in expanding access to contraceptives for adolescent mothers in particular and adolescents, in general, is therefore critical for all countries in SSA with a low prevalence of contraceptive use. 


\section{Strengths and limitations}

The use of large survey data that are nationally representative and the use of a robust statistical method that considered both individual and contextual level factors are important strengths of this study. However, the measure of contraceptive use relied on self-reporting, which is subjected to social desirability bias and could result in under-reporting of use. Also, due to the crosssectional nature of this study, causal link cannot be established. There were differences in the survey years that may affect the accuracy of the comparisons across countries considered in this study.

\section{CONCLUSION}

This study examined contraceptive use prevalence among parenting adolescent girls in SSA. We found wide differences in contraceptive use between countries, with most countries having a low prevalence of contraceptive use. The governments of countries in SSA, particularly in West Africa, should invest in expanding access to contraceptives for adolescent mothers to prevent repeat pregnancy and the overall well-being of girls. Also, we observed evidence of within-country inequalities in access to contraceptives in a few countries. As such, investment in contraceptive access in these countries must focus on ensuring equity, prioritising those that lack access but need it the most.

\section{Author affiliations}

${ }^{1}$ School of Public Health, Faculty of Health, University of Technology Sydney, Sydney, New South Wales, Australia

${ }^{2}$ Faculty of Health Sciences, University of Fort Hare, East London, South Africa

${ }^{3}$ Department of Population and Health, University of Cape Coast, Cape Coast, Ghana ${ }^{4}$ College of Public Health, Medical and Veterinary Sciences, James Cook University,

Townsville, Queensland, Australia

${ }^{5}$ Department of Estate Management, Takoradi Technical Unversity, Takoradi, Ghana ${ }^{6}$ Population Dynamics and Sexual and Reproductive Health, African Population and Health Research Center, Nairobi, Kenya

\section{Twitter Abdul-Aziz Seidu @abdul_aziz10_and Anthony Idowu Ajayi @aiajayi}

Acknowledgements We acknowledge the Demographic Health Surveys for providing us with the data upon which the findings of this study were based.

Contributors AIA conceptualised the study. BOA conducted the data analysis with inputs from A-AS. All authors contributed to the draft, reviewed and approved the final version.

Funding The authors have not declared a specific grant for this research from any funding agency in the public, commercial or not-for-profit sectors.

Competing interests None declared.

Patient consent for publication Not required.

Provenance and peer review Not commissioned; externally peer reviewed.

Data availability statement Data are available in a public, open access repository. The dataset is freely available for download at: https://dhsprogram.com/data/ available-datasets.cfm.

Supplemental material This content has been supplied by the author(s). It has not been vetted by BMJ Publishing Group Limited (BMJ) and may not have been peer-reviewed. Any opinions or recommendations discussed are solely those of the author(s) and are not endorsed by BMJ. BMJ disclaims all liability and responsibility arising from any reliance placed on the content. Where the content includes any translated material, BMJ does not warrant the accuracy and reliability of the translations (including but not limited to local regulations, clinical guidelines, terminology, drug names and drug dosages), and is not responsible for any error and/or omissions arising from translation and adaptation or otherwise.

Open access This is an open access article distributed in accordance with the Creative Commons Attribution Non Commercial (CC BY-NC 4.0) license, which permits others to distribute, remix, adapt, build upon this work non-commercially, and license their derivative works on different terms, provided the original work is properly cited, appropriate credit is given, any changes made indicated, and the use is non-commercial. See: http://creativecommons.org/licenses/by-nc/4.0/.

\section{ORCID iDs}

Bright Opoku Ahinkorah http://orcid.org/0000-0001-7415-895X

Abdul-Aziz Seidu http://orcid.org/0000-0001-9734-9054

Anthony Idowu Ajayi http://orcid.org/0000-0002-6004-3972

\section{REFERENCES}

1 UNICEF. Early childbearing, 2019. Available: https://data.unicef.org/ topic/child-health/adolescent-health/ [Accessed 29 Jun 2019].

2 Norton M, Chandra-Mouli V, Lane C. Interventions for preventing unintended, rapid repeat pregnancy among adolescents: a review of the evidence and lessons from high-quality evaluations. Glob Health Sci Pract 2017;5:547-70.

3 World Bank. Fertility rate, total (births per woman) - Sub-Saharan Africa NW Washington, DC 20433 USA, 2019. Available: https://data. worldbank.org/indicator/SP.DYN.TFRT.IN?locations=ZG [Accessed 20 Mar 2021].

4 Darroch JE, Woog V, Bankole A. Costs and benefits of meeting the contraceptive needs of adolescents Guttmacher İnstitute; 2016.

5 Ajayi Al, Nwokocha EE, Akpan W, et al. Use of non-emergency contraceptive pills and concoctions as emergency contraception among Nigerian university students: results of a qualitative study. BMC Public Health 2016;16:1046.

6 Ajayi Al, Somefun OD. Transactional sex among Nigerian university students: the role of family structure and family support. PLoS One 2019;14:e0210349.

7 Ajayi Al, Ezegbe HC. Association between sexual violence and unintended pregnancy among adolescent girls and young women in South Africa. BMC Public Health 2020;20:1-10.

8 Ajayi Al, Ismail KO, Akpan W. Factors associated with consistent condom use: a cross-sectional survey of two Nigerian universities. BMC Public Health 2019;19:1207.

9 Yarrow E, Anderson K, Apland K, et al. Can a restrictive law serve a protective purpose? The impact of age-restrictive laws on young people's access to sexual and reproductive health services. Reprod Health Matters 2014;22:148-56.

10 Bellizzi S, Pichierri G, Menchini L, et al. The impact of underuse of modern methods of contraception among adolescents with unintended pregnancies in 12 low- and middle-income countries. $J$ Glob Health 2019;9:020429.

11 Lambani MN. Poverty the cause of teenage pregnancy in thulamela municipality. Journal of Sociology and Social Anthropology 2015;6:171-6.

12 Ganchimeg T, Ota E, Morisaki N, et al. Pregnancy and childbirth outcomes among adolescent mothers: a world Health organization multicountry study. BJOG: Int J Obstet Gy 2014;121:40-8.

13 Lee $\mathrm{D}$. The early socioeconomic effects of teenage childbearing: a propensity score matching approach. Demographic Research 2010;23:697-736.

14 Grønvik T, Fossgard Sandøy I. Complications associated with adolescent childbearing in sub-Saharan Africa: a systematic literature review and meta-analysis. PLoS One 2018;13:e0204327.

15 Jonas K, Crutzen R, van den Borne B, et al. Teenage pregnancy rates and associations with other health risk behaviours: a threewave cross-sectional study among South African school-going adolescents. Reprod Health 2016;13:50.

16 Blanc AK, Winfrey W, Ross J. New findings for maternal mortality age patterns: aggregated results for 38 countries. PLoS One 2013;8:e59864.

17 Neal S, Channon AA, Chintsanya J. The impact of young maternal age at birth on neonatal mortality: evidence from 45 low and middle income countries. PLoS One 2018;13:e0195731.

18 Oyeyemi AL, Aliyu SU, Sa'ad F, et al. Association between adolescent motherhood and maternal and child health indices in Maiduguri, Nigeria: a community-based cross-sectional study. BMJ Open 2019;9:e024017.

19 Finlay J, Norton M, Mejía-Guevara I. Adolescent fertility and child health: the interaction of maternal age, parity and birth intervals 
in determining child health outcomes. Int $J$ Child Health Nutr 2017;6:16-33.

20 Korenman S, Fales S. The socioeconomic effects of teenage childbearing: a review of the recent literature. New York City Department of Health and Mental Hygiene; 2011.

21 Birchall J. Early marriage, pregnancy and girl child school dropout. K4D Helpdesk report. Brighton Institute of Development Studies; 2018.

22 Ardington C, Menendez A, Mutevedzi T. Early childbearing, human capital attainment and mortality risk: evidence from a longitudinal demographic surveillance area in rural-KwaZulu-Natal, South Africa. Econ Dev Cult Change 2015;63:281-317.

23 Cook SMC, Cameron ST. Social issues of teenage pregnancy. Obstetrics, Gynaecology \& Reproductive Medicine 2017;27:327-32.

24 Marteleto LJ, Villanueva A. The educational consequences of adolescent childbearing and Union formation in Brazil. Stud Fam Plann 2018;49:183-211.

25 Ajayi Al, Somefun OD. Patterns and determinants of short and long birth intervals among women in selected sub-Saharan African countries. Medicine2020;99:e20118.

26 Conde-Agudelo A, Rosas-Bermudez A, Castaño F, et al. Effects of birth spacing on maternal, perinatal, infant, and child health: a systematic review of causal mechanisms. Stud Fam Plann 2012;43:93-114.

27 de Jonge HCC, Azad K, Seward N, et al. Determinants and consequences of short birth interval in rural Bangladesh: a crosssectional study. BMC Pregnancy Childbirth 2014;14:427.

28 Hall KS, Manu A, Morhe E, et al. Bad girl and unmet family planning need among Sub-Saharan African adolescents: the role of sexual and reproductive health stigma. Qual Res Med Healthc 2018;2:55.

29 Maswikwa B, Richter L, Kaufman J, et al. Minimum marriage age laws and the prevalence of child marriage and adolescent birth: evidence from sub-Saharan Africa. Int Perspect Sex Reprod Health 2015;41:58-68.

30 McKinnon B, Vandermorris A. National age-of-consent laws and adolescent HIV testing in sub-Saharan Africa: a propensity-score matched study. Bull World Health Organ 2019;97:42.

31 Hindin MJ, Kalamar AM, Thompson T-A, et al. Interventions to prevent unintended and repeat pregnancy among young people in low- and middle-income countries: a systematic review of the published and gray literature. J Adolesc Health 2016;59:S8-15.

32 Baa-Poku J. Girls' Re-Entry into School after Pregnancy in the Ashiedu Keteke Sub-Metro District, Accra: Implication for substantive policy. Ghana Social Science 2019;16:71.

33 Sempebwa CS, Tukesiga J, Muhumure D. Protecting Education for Pregnant and Parenting Students: Lessons from a successful intervention in the post-conflict context of Northern Uganda. In: Okwany A, Wazir R, eds. Changing social norms to Universalize girls education in East Africa: lessons from a pilot project. 184. Antwerp, Belgium: Garant Publishers, 2016.

34 Zethraeus N, Dreber A, Ranehill E, et al. A first-choice combined oral contraceptive influences General well-being in healthy women: a double-blind, randomized, placebo-controlled trial. Fertil Steril 2017;107:1238-45

35 Michalow J, Chola L, McGee S, et al. Triple return on investment: the cost and impact of 13 interventions that could prevent stillbirths and save the lives of mothers and babies in South Africa. BMC Pregnancy Childbirth 2015;15:39.

36 Adeniyi OV, Ajayi Al, Somefun OD, et al. Provision of immediate postpartum contraception to women living with HIV in the Eastern
Cape, South Africa; a cross-sectional analysis. Reprod Health 2020;17:1-12.

37 Riley C, Garfinkel D, Thanel K, et al. Getting to FP2020: harnessing the private sector to increase modern contraceptive access and choice in Ethiopia, Nigeria, and DRC. PLoS One 2018;13:e0192522.

38 Corsi DJ, Neuman M, Finlay JE, et al. Demographic and health surveys: a profile. Int J Epidemiol 2012;41:1602-13.

39 National Population Commission [Nigeria] and ICF International. Nigeria demographic and health survey 2018. Abuja, Nigeria, and Rockville, Maryland, USA NPC and ICF International; 2018.

40 Ahinkorah BO. Predictors of modern contraceptive use among adolescent girls and young women in sub-Saharan Africa: a mixed effects multilevel analysis of data from 29 demographic and health surveys. Contraception and Reproductive Medicine 2020;5:1-12.

41 Casey MK, Timmermann L, Allen M, et al. Response and selfefficacy of condom use: a meta-analysis of this important element of AIDS education and prevention. South Commun $J$ 2009;74:57-78.

42 Sserwanja Q, Musaba MW, Mukunya D. Prevalence and factors associated with modern contraceptives utilization among female adolescents in Uganda. BMC Womens Health 2021;21:1-7.

43 Casterline JB, Odden C. Trends in Inter-Birth Intervals in Developing Countries 1965-2014. Popul Dev Rev 2016;42:173-94.

44 Timæus IM, Moultrie TA. On postponement and birth intervals. Population and Development Review 2008;34:483-510.

45 Mejía-Guevara I, Cislaghi B, Weber A, et al. Association of collective attitudes and contraceptive practice in nine sub-Saharan African countries. J Glob Health 2020;10:010705.

46 Dingeta T, Oljira L, Worku A, et al. Low contraceptive utilization among young married women is associated with perceived social norms and belief in contraceptive myths in rural Ethiopia. PLoS One 2021;16:e0247484.

47 Lince-Deroche N, Pleaner M, Morroni C. Achieving universal access to sexual and reproductive health services: the potential and pitfalls for contraceptive services in South Africa. South African Health Review 2016;2016:95-108.

48 Trust SSA. Age of consent: legal review. Botswana Country Report: SAT SRHR Africa Trust, 2018.

49 Rattan J, Noznesky E, Curry DW, et al. Rapid contraceptive uptake and changing method mix with high use of long-acting reversible contraceptives in crisis-affected populations in Chad and the Democratic Republic of the Congo. Glob Health Sci Pract 2016;4 Suppl 2:S5-20.

50 Hahn RA, Truman BI. Education improves public health and promotes health equity. Int J Health Serv 2015;45:657-78.

51 Somani T. Importance of educating girls for the overall development of society: a global perspective. Journal of Educational Research and Practice 2017;7:10.

52 MacDonald K. Calls for educating girls in the Third World: futurity, girls and the 'Third World Woman'. Gender, Place \& Culture 2016;23:1-17.

53 Ajayi Al, Adeniyi OV, Akpan W. Use of traditional and modern contraceptives among childbearing women: findings from a mixed methods study in two southwestern Nigerian states. BMC Public Health 2018:18:604.

54 Ajayi Al, Adeniyi OV, Akpan W. Maternal health care visits as predictors of contraceptive use among childbearing women in a medically underserved state in Nigeria. $J$ Health Popul Nutr 2018;37:19. 